\title{
Gender Differences in Keeping Secrets From Parents in Adolescence
}

\author{
Loes Keijsers, Susan J. T. Branje, and Tom Frijns \\ Utrecht University
}

\author{
Catrin Finkenauer \\ Free University Amsterdam
}

\author{
Wim Meeus \\ Utrecht University
}

\begin{abstract}
The current longitudinal study examined adolescent gender differences in the developmental changes and relational correlates of secrecy from parents. For 4 successive years, starting in the second year of junior high (mean age at Time $1=13.2$ years, $S D=0.51$ ), 149 male and 160 female Dutch adolescents reported on secrecy from their parents and the quality of the parent-child relationship. Latent growth curve modeling revealed a linear increase in secrecy, which was significantly faster for boys than for girls. Moreover, cross-lagged panel analyses showed clear concurrent and longitudinal linkages between secrecy from parents and poorer parent-child relationship quality in girls. In boys, much less strong linkages were found between poorer relationships and secrecy from parents.
\end{abstract}

Keywords: secrecy, gender differences, adolescence, development, parent-child relationship

Throughout adolescence, young people experience an increase in their need for privacy, independence, and autonomy from their parents. Mastering the art of secrecy, or the intentional acts of concealing information from others (Bok, 1989; Kelly, 2002), may play an important facilitating role in this process (Finkenauer, Engels, \& Kubacka, 2008; Finkenauer, Engels, \& Meeus, 2002). Over the course of adolescence, youths may thus increasingly withhold information from their parents, for instance about what they do during unsupervised leisure time. However, secrecy has been identified as poisonous for mutual trust and understanding and is negatively related to the quality of the parent-child relationship (Finkenauer et al., 2008; Finkenauer, Frijns, Engels, \& Kerkhof, 2005; Hinde, 1997; Vangelisti, 1994). Adolescent boys and girls thus have to balance their level of secrecy from parents in terms of gaining independence while staying connected to parents.

Gender differences in the development and relational correlates of secrecy are likely, but longitudinal research on this issue is, to our best knowledge, lacking. Much more is known, to date, about adolescent disclosure (e.g., in relation to parental knowledge; Stattin \& Kerr, 2000). These studies showed that girls disclose more than boys (Keijsers, Branje, Van der Valk, \& Meeus, in press; Soenens, Vansteenkiste, Luyckx, \& Goossens, 2006; Stattin $\&$ Kerr, 2000), that disclosure toward parents decreases with age (Buhrmester \& Prager, 1995; Finkenauer et al., 2002; Keijsers, Frijns, Branje, \& Meeus, 2009; Smetana, Villalobos, Tasopoulos-

Loes Keijsers, Susan J. T. Branje, Tom Frijns, and Wim Meeus, Research Centre Adolescent Development, Utrecht University, Utrecht, the Netherlands; Catrin Finkenauer, Department of Social Psychology, Free University Amsterdam, Amsterdam, the Netherlands.

Correspondence concerning this article should be addressed to Loes Keijsers, Research Centre Adolescent Development, Utrecht University, P.O. Box 80140, 3508 TC Utrecht, the Netherlands. E-mail: 1.keijsers@uu.nl
Chan, Gettman, \& Campione-Barr, 2009; Youniss \& Smollar, 1985), and that open communication and high levels of disclosure facilitate intimacy and trust between relational partners, including both adult relationship partners and parents and children (Finkenauer, Engels, Branje, \& Meeus, 2004; Johnson, 1974; Kerr, Stattin, \& Trost, 1999). However, although secrecy and disclosure are related, they are distinct constructs (Frijns, Finkenauer, Vermulst, \& Engels, 2005; Frijns, Keijsers, Branje, \& Meeus, in press; Smetana, Metzger, Gettman, \& Campione-Barr, 2006). Longitudinal research on developmental aspects and relational consequences of secrecy for adolescent boys and girls is thus warranted. The current study was intended to fill this gap in our knowledge.

\section{Development of Secrecy}

Parent-child communication changes during adolescence, and so does secrecy from parents about leisure time activities and whereabouts. In the current study, we focused on leisure time activities and secrecy surrounding such activities. Youths' engagement in leisure time activities without adult supervision increases during this developmental phase (Larson, Richards, Moneta, Holmbeck, \& Duckett, 1996; Osgood, Wilson, O’Malley, Bachman, \& Johnston, 1996), and secrecy regarding these activities may thus be of particular interest.

Adolescents are in a phase in which they develop into autonomous individuals with identities separate from their parents (Blos, 1967; Erikson, 1950). To do so, they establish boundaries around information they consider personal and may choose to withhold private information (Petronio, 2002; Youniss \& Smollar, 1985). Two cross-sectional studies (Smetana et al., 2006, 2009) confirmed that adolescents increasingly consider some information as private or personal and as legitimate to withhold from their parents. Hence, an increase in secrecy surrounding leisure time activities is to be expected during adolescence. Surprisingly, to our best knowledge, no longitudinal studies have examined the development of secrecy from parents among adolescents, and the few 
cross-sectional studies did not find that younger and older adolescents differed in levels of secrecy (Finkenauer et al., 2002; Smetana et al., 2006). However, these studies have some limitations. They did not examine within-person change or examine whether the development of secrecy is linear or curvilinear.

In addition, gender differences in the development of secrecy are not well examined. Although no mean level gender differences are typically found in cross-sectional studies on secrecy from parents (Finkenauer et al., 2002, 2005, 2008; Frijns et al., 2005), one cross-sectional study (Smetana et al., 2006) suggests that secrecy from parents may develop differently for adolescent boys and girls and that such gender differences become more pronounced with age. Smetana et al. (2006) showed that 12th-grade boys had more secrets from parents about schoolwork than did 12th-grade girls, whereas no such gender differences were found among ninth graders. Further, it showed that secrecy about school issues increased with age for adolescent boys but not for girls, suggesting that increasing gender differences in levels of boys' and girls' secrecy are due to a faster increase in secrecy from parents for boys. There are to date no longitudinal studies to substantiate this idea. Therefore, the first aim in this study was to examine gender differences in the within-person mean level development of secrecy.

\section{Relational Correlates of Secrecy}

Healthy individuation is achieved when adolescents develop independence without having to cut off their relationships with their parents. That is, adolescents have to develop a healthy balance between autonomy from parents and ties with parents (Blos, 1967; Geuzaine, Debry, \& Liesens, 2000). There is thus a paradoxical tension between the facts that secrecy may play a role in gaining independence from parents in adolescence and that secrecy can be poisonous for mutual trust and understanding (Finkenauer et al., 2005, 2008; Hinde, 1997). Empirical studies on the relational consequences of adolescent secrecy from parents are scarce (Finkenauer et al., 2008; cf. Vangelisti, 1994, on family secrets), but the few cross-sectional studies among adolescents have found that having more secrets was related to worse parent-child relationships in terms of parental supportiveness, acceptance, and involvement (Finkenauer et al., 2005; Frijns et al., 2005).

Given that secrecy can promote independence but damages connectedness, gender differences in these relational aspects of secrecy can be expected. Connectedness to parents plays a central role in the development of female adolescents, whereas this is less the case for male adolescents. Girls, compared to boys, are found to be more dependent on the relationship with their parents and more in need of emotional support from their caregivers (e.g., Chodorow, 1978; Geuzaine et al., 2000; Moore, 1987). During adolescence, girls remain closer to their parents than do boys (e.g., Ryan \& Lynch, 1989). Indeed, empirical studies show that parentchild relationships with daughters are characterized by more intimacy and reciprocity (e.g., Youniss \& Smollar, 1985) than are relationships with sons. The second aim in this study was to explore whether there are gender differences in the longitudinal associations between secrecy and relationship quality with parents.

The aim in this longitudinal study was to examine gender differences in within-person mean level development and relational correlates of secrecy from parents during adolescence. We hypothesized that secrecy increases during middle adolescence, and, based on a previous study (Smetana et al., 2006), we expected that this increase would be faster for boys than for girls. In this study we explored, without a priori hypotheses, whether the shape of this development is linear or curvilinear. We further hypothesized that secrecy would be related to poorer relationship quality over time. We explored whether and how these linkages between secrecy and relationship quality vary by adolescent gender without a priori hypotheses, because previous studies did not examine such gender differences.

\section{Method}

\section{Participants}

Data for the current study came from a subsample of an ongoing longitudinal study on relationships in adolescence, named CONflict And Management Of RElationships (CONAMORE; Meeus et al., 2004), in which 938 adolescents have participated in annual assessments at their schools for 5 consecutive years. All 656 native Dutch two-parent families in this study were invited to participate in additional annual home visits, and 401 of them accepted our invitation. Because of financial restrictions on the study budget, 323 of these families were randomly selected. Four annual waves of questionnaire data were collected in these families. Of these families, those that were still two-parent families at the start of the home visits, 1 year after the selection, were included in the current study $(n=309)$.

The 149 boys and 160 girls in our sample came from various high schools located in municipalities in an urban area in the Netherlands. At the first measurement (Time 1), the adolescents had a mean age of 13.2 years $(S D=0.51)$ and were in the second year of junior high. All families were two-parent families, and the majority of adolescents (99.0\%) lived with both biological parents. Of the fathers, $1.7 \%$ did not finish high school, $23.9 \%$ graduated from high school, $38.1 \%$ graduated from middle or higher level vocational/technical training, and $35.6 \%$ had a university degree. Of the mothers, $0.7 \%$ did not finish high school, $35.0 \%$ graduated from high school, $41.9 \%$ graduated from middle or higher vocational/technical training, and $21.1 \%$ had a university degree.

Attrition effects were tested by comparing characteristics of the sample $(n=309)$ with adolescents from Dutch two-parent families from the larger sample who were not participating in home visits $(n=347)$. A two-tailed $t$ test revealed no age differences, $t(645)=$ $-1.88, p=.06$, and chi-square tests revealed no differences in gender composition, $\chi^{2}(1, N=656)=0.74, p=.39$, or the educational level of fathers, $\chi^{2}(6, N=625)=11.90, p=.11$. However, mothers in our sample had higher educational levels than did mothers in the comparison sample, $\chi^{2}(6, N=629)=$ $20.78, p=.02$. In addition, no attrition effects were found on relationship quality $(t \mathrm{~s}<1.59, \mathrm{ps}>.11)$. Secrecy was not assessed in the larger sample.

\section{Procedure}

Before the study, adolescents from various participating high schools and their parents received written information about the study and provided written informed consent. Adolescents filled out questionnaires during school visits after school hours and during home 
visits in which parents also participated. Trained research assistants provided verbal instructions in addition to the written instructions that accompanied the large battery of questionnaires. Families received the equivalent of US \$35 per home visit, and adolescents received the equivalent of US \$13 per school assessment.

\section{Measures}

Secrecy. The extent to which adolescents conceal information from their parents was assessed with adolescent reports. Two secrecy items were extracted from the five-item child disclosure scale developed by Kerr and Stattin (2000; Stattin \& Kerr, 2000), namely, "Do you keep a lot of secrets from your parents about what you do during your free time?" and "Do you hide a lot from your parents about what you do during nights and weekends? Questions were rated on 5-point Likert scales, ranging from 1 (never) to 5 (often). The correlation between the secrecy items ranged from $r=.60$ to $r=.64$ across waves ( $\alpha$ s $=.67-.77)$. The validity of this two-item composite score has been extensively discussed by Frijns et al. (in press). Their confirmatory factor analyses revealed that the original five-item disclosure scale of Stattin and Kerr was actually composed of two underlying factors, namely, a two-item secrecy factor and a three-item disclosure factor (fit of two-factor model, $\chi^{2}(4)=6.29$; Tucker-Lewis In$\operatorname{dex}=.98$, Root Mean Square Error of Approximation $=.04$ ). In comparison to the three-item disclosure measure, this two-item secrecy measure was found to relate to higher levels of delinquency and depression. ${ }^{1}$

Adolescents reported on the relationship quality with their parents, using a 12-item support scale of the Network of Relationships Inventory for each parent (De Goede, Branje, \& Meeus, 2009; Furman \& Buhrmester, 1985). Adolescents indicated on 5-point Likert scales $(1=$ little or none to $5=$ more is impossible $)$ the degree to which they perceived support within their relationship with their father and mother. An example item is "Does your mother like or approve of the things you do?" The correlation between adolescent reports of support from fathers and from mothers was very strong ( $r$ s $=.71-.77$ across waves), and we averaged these scores to overcome issues of multicollinearity. Reliability of this composite score was high over the measurement waves $(\alpha \mathrm{s}=.82-.91)$.

At the fourth measurement, 308 families (99.7\%) were still involved in the study. That is, at Time 4 there were 299 families in which all members filled out the questionnaires, and another 9 families in which one or two family members participated. Over the four measurements, $87.7 \%$ of the respondents had no missing values and a maximum of $3.6 \%$ of the cases was missing per variable. Because values were found to be missing completely at random (Little's MCAR test, $\chi^{2}(59)=69.95, p=.16$ ), respondents with missing values could be included in models that were estimated using a Full Information Maximum Likehood procedure in Mplus (Bollen \& Curran, 2006, p. 65; Enders \& Bandalos, 2001).

\section{Results}

\section{Development of Secrecy for Boys and Girls}

Mean levels of secrecy and parent-child relationship quality for boys and girls are presented in Table 1 . One small gender differ- ence in adolescents' secrecy from parents was found over four measurements. At Time 4 (modal age 16), boys reported more secrecy than did girls, $F(1,299)=4.53, p=.03, \eta^{2}=.02$. No significant mean level gender differences were found in parentchild relationship quality.

We tested the development of secrecy for boys and girls using two-group Latent Growth Curve Modeling (in which groups were defined by adolescent gender). In this type of analysis, linear growth is expressed by two latent growth factors, namely, an intercept (i.e., mean level) and a slope (i.e., rate of change). ${ }^{2} \mathrm{We}$ also tested nonlinear models, by adding a quadratic slope term or freely estimating the shape of growth. Neither procedure significantly improved model fit in terms of lower chi-square. Hence, the linear model was more parsimonious and therefore superior.

Gender differences in development of secrecy were examined by constraining the mean slope to be equal for boys and girls. A significantly higher chi-square (i.e., worse fit) of this constrained model compared to the initial unconstrained model would indicate that development differs for adolescent boys and girls. Table 2 displays how boys' and girls' secrecy increased linearly between ages 13 and 16 (estimated mean annual increase was .09 for girls and .18 for boys). In line with our hypotheses, this increase in secrecy from parents between ages 13 and 16 was significantly faster for boys than for girls.

\section{Secrecy and Relationship Quality for Boys and Girls}

Longitudinal associations of secrecy with relationship quality were examined with two-group cross-lagged panel analyses (for an introduction, see Kline, 2005). This model included four waves of self-reported secrecy and perceived relationship quality. We estimated Time 1 associations (interpreted as correlations at Time 1), 1- and 2-year stability (interpreted as relative stability over time), correlated change (interpreted as overlapping relative change in two variables), and cross-lagged paths between secrecy and relationship quality (interpreted as a linkage of the level of one variable at a given year with a relative change in another variable a year later). Correlated change and cross-lagged paths reflect longitudinal relationships and were interpreted as such. Preliminary analyses on the model revealed that cross paths and correlated changes were invariant in time. When these paths were constrained, chi-square model fit did not significantly improve. Therefore these paths were constrained to be equal across intervals. Fit of this more parsimonious model remained good.

\footnotetext{
${ }^{1}$ Visual inspection of the histograms revealed that the secrecy measure was somewhat positively skewed at the first measurement but that kurtosis as well as the skewness in all other waves was well within the acceptable range (Tabachnick \& Fidell, 2001, p. 75). Zero-based skewness and kurtosis values $(S E)$ were as follows: skewness Time $1_{1}=1.17(0.14)$, skewness $_{\text {Time } 2}=0.76$ (0.14), skewness Time 3 $_{3}=0.41(0.14)$, and skewness Time $4_{4}=0.36(0.14)$; kurtosis $_{\text {Time 1 }}=1.73(0.28)$, kurtosis $_{\text {Time 2 }}=0.44(0.28)$, kurtosis $_{\text {Time 3 }}=$ $-0.25(0.28)$, and kurtosis Time $4=-0.25(0.28)$.

${ }^{2}$ To model linear development with Latent Growth Curve Modeling, we set factor loadings of the four measurements of secrecy on the intercept factor at $1 ; 1 ; 1 ; 1$ and factor loadings on the slope factor at $0 ; 1 ; 2 ; 3$. No intercept-slope associations were modeled. An introduction to this technique can be found in Duncan, Duncan, Stryker, Li, and Alpert (1999) or Bollen and Curran (2006).
} 
Table 1

Means and Standard Deviations of the Study Variables

\begin{tabular}{|c|c|c|c|c|c|c|c|c|}
\hline \multirow[b]{2}{*}{ Variable } & \multicolumn{2}{|c|}{ Time 1} & \multicolumn{2}{|c|}{ Time 2} & \multicolumn{2}{|c|}{ Time 3} & \multicolumn{2}{|c|}{ Time 4} \\
\hline & Boys & Girls & Boys & Girls & Boys & Girls & Boys & Girls \\
\hline \multicolumn{9}{|c|}{ Secrecy from parents } \\
\hline$M$ & 1.68 & 1.75 & 1.93 & 1.92 & 2.03 & 1.91 & $2.23_{\mathrm{a}}$ & $2.05 \mathrm{~b}$ \\
\hline$S D$ & 0.69 & 0.67 & 0.73 & 0.74 & 0.70 & 0.66 & 0.68 & $0.79^{\circ}$ \\
\hline \multicolumn{9}{|c|}{ Relationship quality } \\
\hline$M$ & 3.55 & 3.61 & 3.52 & 3.55 & 3.41 & 3.47 & 3.41 & 3.48 \\
\hline$S D$ & 0.53 & 0.57 & 0.59 & 0.58 & 0.57 & 0.63 & 0.53 & 0.61 \\
\hline
\end{tabular}

Note. Within rows, means with different subscripts are significantly different for boys and girls. Correlation tables can be obtained upon request from Loes Keijsers.

Higher levels of self-reported secrecy from parents were clearly related to lower relationship quality for girls, both concurrently (i.e., strong negative Time 1 associations) and longitudinally (i.e., small negative correlated change, moderately strong cross paths from secrecy to poorer relationship quality, and moderately strong cross paths from poorer relationship quality to secrecy; see Table 3 ). The negative cross-lagged paths from secrecy to relationship quality were significantly weaker than the reverse paths from relationship quality to secrecy $\left(\chi^{2}(1, N=309)=9.40, p<.01\right)$, suggesting that the effect from poorer relationships on higher levels of secrecy is stronger than the negative effect that secrecy has on relationship quality in girls. In boys, there was no Time 1 association; relationship quality did not significantly predict secrecy over time, nor was secrecy a predictor of relationship quality. Only correlated change was significant, though it was small.

Furthermore, two-group analyses, in which an unconstrained model was compared with models in which one set of parameters was constrained to be equal for boys and girls, showed that Time 1 associations, cross paths from secrecy to relationship quality, and cross paths from relationship quality to secrecy were significantly stronger for girls than for boys. Yet, no gender differences were found on correlated changes. Overall, these findings show that there is a stronger cross-sectional and longitudinal linkage between secrecy and poorer parent-child relationships among girls than among boys.

\section{Discussion}

The current four-wave study highlighted gender differences in adolescents' secrecy from parents. In line with findings of other studies (Finkenauer et al., 2002; Frijns et al., 2005; Smetana et al. 2006), overall gender differences in the level of self-reported secrecy were absent or small. Secrecy from parents increased during middle adolescence, and this increase in secrecy was faster in boys than in girls. Moreover, secrecy and poorer relationship quality were longitudinally and bidirectionally related in girls Among boys, cross-sectional links were not found and longitudinal linkages were less strong than among girls. These findings are discussed below in terms of developmental processes during adolescence for boys and girls.

\section{Why Does Secrecy Increase?}

Previous studies have shown that parent-child communication changes over the course of adolescence. Driven by the increasing need for autonomy and independence, adolescents establish boundaries around information they consider personal (Petronio, 2002; Youniss \& Smollar, 1985) and want to keep secret from parents (Finkenauer et al., 2002, 2008; Frijns et al., 2005; Marshall, Tilton-Weaver, \& Bosdet, 2005). This study was the first longitudinal study to show that levels of secrecy from parents indeed increase during adolescence.

We propose that the increase in boys' secrecy is stronger than the increase in girls' secrecy because the costs of having a secret are higher for girls than for boys, in terms of damaged parentchild relationship quality. However, the advantages of secrecy in terms of higher emotional autonomy are equal for boys and girls. That is, connectedness to parents plays a central role in the development of female adolescents, and empirical studies show that girls' relationships with parents are characterized by more

Table 2

Estimated Intercepts and Rates of Change Derived From Two-Group Latent Growth Models on Four Successive Measurements of Secrecy

\begin{tabular}{|c|c|c|c|c|c|c|c|c|c|c|c|c|}
\hline \multirow[b]{2}{*}{ Model } & \multicolumn{6}{|c|}{ Intercept } & \multicolumn{6}{|c|}{ Slope (change rate) } \\
\hline & $M$ & $S E$ & $p$ & $\sigma^{2}$ & $S E$ & $p$ & $M$ & $S E$ & $p$ & $\sigma^{2}$ & $S E$ & $p$ \\
\hline Boys' secrecy & 1.71 & 0.06 & $<.001$ & .23 & .04 & $<.001$ & 0.18 & 0.02 & $<.001$ & .00 & .01 & .44 \\
\hline Girls'secrecy & 1.77 & 0.05 & $<.001$ & .24 & .04 & $<.001$ & 0.09 & 0.02 & $<.001$ & .02 & .01 & $<.01$ \\
\hline Gender difference $\left(\Delta \chi^{2}, d f, p\right)$ & 0.69 & 1 & .41 & & & & 9.91 & 1 & $<.01$ & & & \\
\hline
\end{tabular}

Note. $\quad \sigma^{2}$ is the variance around growth factors. Confidence intervals $=$ mean $\pm(S E \times 1.96)$. Model fit of this linear model was adequate: Comparative Fit Index $=.97$; Tucker-Lewis Index $=.96$; Root Mean Square Error of Approximation $=.08 ; S E=$ standard error. 
Table 3

Cross-Lagged Panel Analyses of Secrecy From Parents With Parent-Child Relationship Quality

\begin{tabular}{|c|c|c|c|c|c|c|}
\hline \multirow[b]{2}{*}{ Parameter } & \multicolumn{3}{|c|}{ Boys } & \multicolumn{3}{|c|}{ Girls } \\
\hline & $B$ & $S E$ & $\beta$ & $B$ & $S E$ & $\beta$ \\
\hline \multicolumn{7}{|l|}{$\mathrm{T} 1$ associations and correlated change } \\
\hline $\mathrm{T} 1$ secrecy $\leftrightarrow \mathrm{T} 1$ relationship quality & $-0.03_{\mathrm{a}}$ & .03 & -.09 & $-0.17_{\mathrm{b}}$ & .04 & $-.44^{* * * * *}$ \\
\hline $\mathrm{T} 2$ secrecy $\leftrightarrow \mathrm{T} 2$ relationship quality & $-0.02^{a}$ & .01 & $-.05^{*}$ & -0.03 & .01 & $-.06^{*}$ \\
\hline T3 secrecy $\leftrightarrow$ T3 relationship quality & -0.02 & .01 & $-.06^{*}$ & -0.03 & .01 & $-.06^{*}$ \\
\hline $\mathrm{T} 4$ secrecy $\leftrightarrow \mathrm{T} 4$ relationship quality & -0.02 & .01 & $-.06^{*}$ & -0.03 & .01 & $-.05^{*}$ \\
\hline \multicolumn{7}{|l|}{ Cross-lagged paths } \\
\hline $\mathrm{T} 1$ secrecy $\rightarrow \mathrm{T} 2$ relationship quality & $-0.01_{\mathrm{a}}$ & .03 & -.01 & $-0.09 \mathrm{~b}$ & .03 & $-.10^{* *}$ \\
\hline $\mathrm{T} 2$ secrecy $\rightarrow \mathrm{T} 3$ relationship quality & $-0.01_{\mathrm{a}}$ & .03 & -.01 & $-0.09_{b}$ & .03 & $-.10^{* *}$ \\
\hline $\mathrm{T} 3$ secrecy $\rightarrow \mathrm{T} 4$ relationship quality & $-0.01_{\mathrm{a}}^{a}$ & .03 & -.01 & $-0.09 \mathrm{~b}$ & .03 & $-.09^{* *}$ \\
\hline $\mathrm{T} 1$ relationship quality $\rightarrow \mathrm{T} 2$ secrecy & $-0.09 \mathrm{a}$ & .05 & -.06 & $-0.25_{\mathrm{b}}$ & .05 & $-.19^{* * * * *}$ \\
\hline $\mathrm{T} 2$ relationship quality $\rightarrow \mathrm{T} 3$ secrecy & $-0.09 \mathrm{a}$ & .05 & -.07 & $-0.25_{\mathrm{b}}$ & .05 & $-.22^{* * * *}$ \\
\hline $\mathrm{T} 3$ relationship quality $\rightarrow \mathrm{T} 4$ secrecy & $-0.09 \mathrm{a}$ & .05 & -.08 & $-0.25 \mathrm{~b}$ & .05 & $-.20^{* * * *}$ \\
\hline
\end{tabular}

Note. Within rows, paths with different subscripts differ for boys and girls (i.e., chi-square fit statistics increased significantly when these paths were constrained to be equal for boys and girls). Model fit: Comparative Fit Index $=.99$; Tucker-Lewis Index $=.98$; Root Mean Square Error of Approximation $=.05$. One- and 2-year stability paths were estimated but were omitted from this table. Confidence intervals $=B \pm(S E \times 1.96)$. T1 $=$ first measurement; $\mathrm{T} 2=$ second measurement; $\mathrm{T} 3=$ third measurement; $\mathrm{T} 4=$ fourth measurement; $S E=$ standard error.

${ }^{*} p<.05{ }^{* *} p<.01 . \quad{ }^{* * *} p<.001$.

intimacy and reciprocity (Chodorow, 1978; Youniss \& Smollar, 1985) than are boys' relationships with parents. Moreover, girls are found to be more dependent on the parent-child relationship and to need higher levels of emotional support from their caregivers (Geuzaine et al., 2000; Ryan \& Lynch, 1989). For girls, there is thus an ongoing ambivalence between dependence and demand for autonomy. When weighing the benefits of secrecy (i.e., higher autonomy) against the high costs (i.e., poorer relationships with the person who gives you emotional support), girls may thus more often choose to reveal personal information than to keep it secret. Boys are less concerned about connectedness with their parents, and their secrecy may thus increase along with their increasing need for autonomy and independence. However, the gender difference in the mean level of secrecy at age 16 was small in the current study, and future follow-up research is needed to clarify whether this gender difference in secrecy becomes more pronounced in late adolescence and emerging adulthood, as the current findings suggest.

\section{Secrecy and Poorer Parent-Child Relationships}

We also showed that linkages between poorer relationships and secrecy were stronger for girls than for boys. We believe that this gender difference too could result from the fact that girls have more intimate relationships with their parents than do boys (e.g., Youniss \& Smollar, 1985). Secrecy can create a distance between the secret keeper and the other and could be an indication that the relationship with the target is nonintimate (otherwise, the secret would have been shared; Vangelisti, 1994). For instance, not sharing private matters with a neighbor one hardly knows is normative and well accepted, whereas not sharing the same matters with an intimate partner may be seen a sign of lack of trust or commitment. Hence, the pressure to share information is likely to be higher when relationships are more intimate, because having secrets in these relationships is less normative and can be interpreted by the other as undermining the quality of the relationship. Our findings also indicated that poorer relationships are not only the result of high levels of secrecy; poorer relationships also preceded higher levels of secrecy, and secrecy and poorer relationships were thus intertwined. In fact, in girls, secrecy from parents can therefore be considered as a marker of poorer relationship quality in previous years but also as a predictor of poorer relationships with parents in future years. In boys, higher levels of secrecy do not necessarily indicate relationship problems.

\section{Strengths and Limitations}

The current four-wave study was, to our knowledge, the first to examine the development of secrecy using longitudinal data. However, some limitations should be mentioned. First, we had only two secrecy items in our data set. These items were extracted from the child disclosure scale by Stattin and Kerr (2000) and have been shown to have adequate divergent validity (Frijns et al., in press). However, there is no good way to examine the factor structure of a two-item construct; hence, the internal validity of this construct is unknown. Further, because we had access to only these two items, we could address secrecy only in the leisure domain. Studies by Smetana and colleagues (Smetana et al., 2006, 2009) have shown that secrecy varies by peer, school, and personal domain, and future studies may extend our knowledge by including secrecy items in different domains. Second, children reported on secrecy from both parents. Consequently, conclusions about specific parent-child dyads could not be made from the current study.

Despite these limitations, we believe, this study is a solid first attempt to direct attention to the often-ignored gender differences in secrecy. It has clearly shown that, although no mean-level gender differences emerged, boys' secrecy from parents increases more rapidly and was less strongly linked to worse relationship quality than was girls' secrecy. As such, our results suggest that it 
would be unwise for future studies to dismiss gender differences when no mean level differences are found. They moreover suggest that secrecy in girls may be a marker and a longitudinal predictor of relationship problems, whereas high levels of secrecy in boys may reflect individuation rather than relationship issues.

\section{References}

Blos, P. (1967). The second individuation process of adolescence. In The adolescent passage (pp. 161-170). New York, NY: International University Press.

Bok, S. (1989). Secrets: On the ethics of concealment and revelation. New York, NY: Vintage Books.

Bollen, K. A., \& Curran, P. J. (2006). Latent curve models: A structural equation perspective. Hoboken, NJ: Wiley.

Buhrmester, D., \& Prager, K. (1995). Patterns and functions of selfdisclosure during childhood and adolescence. In K. J. Rotenberg (Ed.), Disclosure processes in children and adolescents (pp. 10-56). New York, NY: Cambridge University Press.

Chodorow, N. J. (1978). The reproduction of mothering: Psychoanalysis and the sociology of gender. Berkeley, CA: University of California Press.

De Goede, I., Branje, S., \& Meeus, W. (2009). Developmental changes in adolescents' perceptions of relationships with their parents. Journal of Youth and Adolescence, 38, 75-88.

Duncan, T. E., Duncan, S. C., Strycker, L. A., Li, F., \& Alpert, A. (1999). An introduction to latent variable growth curve modeling: Concepts, issues, and applications (2nd ed.). Mahwah, NJ: Erlbaum.

Enders, C. K., \& Bandalos, D. L. (2001). The relative performance of full information maximum likelihood estimation for missing data in structural equation models. Structural Equation Modeling, 8, 430-457.

Erikson, E. (1950). Childhood and society. New York, NY: Norton.

Finkenauer, C., Engels, R. C. M. E., Branje, S. J. T., \& Meeus, W. (2004). Disclosure and relationship satisfaction in families. Journal of Marriage and Family, 66, 195-209.

Finkenauer, C., Engels, R., \& Kubacka, K. (2008). Relational implications of secrecy and concealment in parent-adolescent relationships. In M. Kerr, H. Stattin, \& R. Engels (Eds.), What can parents do? New insights into the role of parents in adolescent problem behavior (pp. 42-64). Chichester, England: Wiley.

Finkenauer, C., Engels, R. C. M. E., \& Meeus, W. (2002). Keeping secrets from parents: Advantages and disadvantages of secrecy in adolescence. Journal of Youth and Adolescence, 31, 123-136.

Finkenauer, C., Frijns, T., Engels, R. C. M. E., \& Kerkhof, P. (2005). Perceiving concealment in relationships between parents and adolescents: Links with parental behavior. Personal Relationships, 12, 387406

Frijns, T., Finkenauer, C., Vermulst, A. A., \& Engels, R. C. M. E. (2005). Keeping secrets from parents: Longitudinal associations of secrecy in adolescence. Journal of Youth and Adolescence, 34, 137-148.

Frijns, T., Keijsers, L., Branje, S. J. T., \& Meeus, W. (in press). What parents don't know and how it may affect their children: Qualifying the disclosure-adjustment link. Journal of Adolescence. Advance online publication. doi:10.1016/j.adolescence.2009.05.010

Furman, W., \& Buhrmester, D. (1985). Children's perceptions of the personal relationships in their social networks. Developmental Psychology, 21, 1016-1024.

Geuzaine, C., Debry, M., \& Liesens, V. (2000). Separation from parents in late adolescence: The same for boys and girls? Journal of Youth and Adolescence, 29, 79-91.

Hinde, R. (1997). Relationships: A dialectic perspective. Hove, England: Psychology Press.

Johnson, C. (1974). Privacy as personal control. In S. T. Margulis (Ed.),
Privacy (pp. 83-100). Stony Brook, NY: Environmental Design Research Association.

Keijsers, L., Branje, S. J. T., Van der Valk, I. E., \& Meeus, W. (in press). Reciprocal effects between parental solicitation, parental control, adolescent disclosure, and adolescent delinquency. Journal of Research on Adolescence.

Keijsers, L., Frijns, T., Branje, S. J. T., \& Meeus, W. (2009). Developmental links of adolescent disclosure, parental solicitation, and control with delinquency: Moderation by parental support. Developmental Psychology, 45, 1314-1327.

Kelly, A. E. (2002). The psychology of secrets. New York, NY: Kluwer Academic/Plenum.

Kerr, M., \& Stattin, H. (2000). What parents know, how they know it, and several forms of adolescent adjustment: Further support for a reinterpretation of monitoring. Developmental Psychology, 36, 366-380.

Kerr, M., Stattin, H., \& Trost, K. (1999). To know you is to trust you: Parents' trust is rooted in child disclosure of information. Journal of Adolescence, 22, 737-752.

Kline, R. B. (2005). Principles and practice of structural equation modeling (2nd ed.). New York, NY: Guilford Press.

Larson, R. W., Richards, M. H., Moneta, G., Holmbeck, G., \& Duckett, E. (1996). Changes in adolescents' daily interactions with their families from ages 10 to 18: Disengagement and transformation. Developmental Psychology, 32, 744-754.

Marshall, S. K., Tilton-Weaver, L. C., \& Bosdet, L. (2005). Information management: Considering adolescents' regulation of parental knowledge. Journal of Adolescence, 28, 633-647.

Meeus, W., Akse, J., Branje, S., ter Bogt, T., Delsing, M., Doorn, M., . . . Spruijt, E. (2004). Codebook of the research project Conflicts and Management of Relationships (CONAMORE). Utrecht, the Netherlands: Utrecht University, Faculty of Social Sciences.

Moore, D. (1987). Parent-adolescent separation: The construction of adulthood by late adolescents. Developmental Psychology, 23, 298-307.

Osgood, D. W., Wilson, J. K., O'Malley, P. M., Bachman, J. G., \& Johnston, L. D. (1996). Routine activities and individual deviant behavior. American Sociological Review, 61, 635-655.

Petronio, S. (2002). Boundaries of privacy: Dialectics of disclosure. Albany, NY: State University of New York Press.

Ryan, R. M., \& Lynch, J. H. (1989). Emotional autonomy versus detachment: Revisiting the vicissitudes of adolescence and young adulthood. Child Development, 60, 340-356.

Smetana, J. G., Metzger, A., Gettman, D. C., \& Campione-Barr, N. (2006). Disclosure and secrecy in adolescent-parent relationships. Child Development, 77, 201-217.

Smetana, J. G., Villalobos, M., Tasopoulos-Chan, M., Gettman, D. C., \& Campione-Barr, N. (2009). Early and middle adolescents' disclosure to parents about activities in different domains. Journal of Adolescence, 32 693-713.

Soenens, B., Vansteenkiste, M., Luyckx, K., \& Goossens, L. (2006). Parenting and adolescent problem behavior: An integrated model with adolescent self-disclosure and perceived parental knowledge as intervening variables. Developmental Psychology, 42, 305-318.

Stattin, H., \& Kerr, M. (2000). Parental monitoring: A reinterpretation. Child Development, 71, 1072-1085.

Tabachnick, B. G., \& Fidell, L. S. (2001). Using multivariate statistics (4th ed.). Needham Heights, MA: Allyn \& Bacon.

Vangelisti, A. L. (1994). Family secrets: Forms, functions and correlates. Journal of Social and Personal Relationships, 11, 113-135.

Youniss, J., \& Smollar, J. (1985). Adolescent relations with mothers, fathers, and friends. Chicago, IL: University of Chicago Press.

Received February 11, 2009

Revision received August 17, 2009

Accepted October 2, 2009 